\title{
Hijab from the Mystical Approach of Halqeh Mysticism
}

\author{
Mohammad Ali Taheri
}

\begin{abstract}
The topic of veiling is very complex and lengthy, and it can be explored from two perspectives, quantitative (outer view) and qualitative (inner view). The quantitative aspect of veiling is discussed in religion, and it has been deemed necessary in different ways in all divine books. But aside from obeying the religious laws (the principles of the way of God), the qualitative aspect of this obedience (the quality of the way of God) is also important, and ignoring or not paying sufficient attention to it would prevent achieving the sufficient result, and is not true religiosity. In other words, the apparent keeping and obeying of the religious laws and orders is not sufficient, and transcendence, results from obeying both inner as well as the outer aspects of the religion. In the qualitative examination of veiling, subjects like 'energy of the second type,' 'attraction and repulsion,' and 'the inner value' are much discussed.
\end{abstract}

Index Terms-Energy of the second type, halqeh mysticism, hijab, kamal, worldview.

\section{InTROdUCtION (PHILOSOPHY OF HiJAB)}

Every gain from the universe has a repayment in alms, which is a proportionate reflection to that gain. In other words, the universe has provided everyone means and talents that demand gratitude. This gratitude is in the form of alms, meaning returning a gift to the universe. Therefore, in response to everything that benefits us or helps us in a way, we owe alms: the alms for science, beauty, good marriage and children, wealth, fame, and so on.

The philosophy of hijab and the veil is avoiding ostentation which is itself considered a type of alms-giving. In fact, veiling prevents ostentation and the creation of its faulty consciousness ${ }^{1}$, so that in this path, the human being is able to donate gifts (alms) to the universe that are appropriate to the universe's dignity. In this viewpoint, veiling encompasses all human beings including both woman and man. Such hijab is a result of needlessness and mystical wealth; thus, one who reaches mystical maturity obeys the rules of veiling.

\section{Qualitative Aspect of HiJab}

The topic of veiling is very complex and lengthy, and it

Manuscript received April 12, 2013; revised June 20, 2013.

Mohammad Ali Taheri is with Taman Universiti Johor, Malaysia (e-mail: mataheri2011@gmail.com).

${ }^{1}$ In any given time there are three elements in the material universe: Awareness (Consciousness), Matter, and Energy. For example, without Awareness, the human being cannot exploit Matter and Energy. This means that if Matter and Energy would be available to a human being, without Awareness and information he could not use Matter or Energy purposefully. Therefore, the ultimate structure of the material universe is the intelligence or consciousness from which Matter and Energy are formed.(For details please refer to 'Human from another Outlook,', by M.A. Taheri) can be explored from two perspectives, quantitative (outer view) and qualitative (inner view) [1]. The quantitative aspect of veiling is discussed in religion, and it has been deemed necessary in different ways in all divine books. But aside from obeying the religious laws (the principles of the way of God), the qualitative aspect of this obedience (the quality of the way of God) is also important and ignoring or not paying sufficient attention to it would prevent achieving the sufficient results, and is not true religiosity. In other words, the apparent keeping and obeying of the religious laws and orders is not sufficient, and transcendence, results from obeying both inner as well as the outer aspects of the religion.

In the qualitative examination of veiling, subjects such as 'energy of the second type,' 'attraction and repulsion,' and 'the inner value' are much discussed.

\section{The ENERGY OF THE SECOND TyPe}

The normal person, aside from the energy of the consumed food which is called 'the energy of the first type', is in need of other kinds of energy. Meaning, even after having complete meals and enough rest, in addition to satisfying all his physical needs, he still faces deficiencies which cause lack of satisfaction. One of these energies is 'the energy of the second type' which is gained upon being praised, commended, noticed and admired by others. For instance, a normal person becomes completely happy by hearing a pleasant comment and totally unsatisfied (uncharged) by hearing an unpleasant statement, and loses his energy.

A person who, in this life, does not have an transcendent motivation ${ }^{2}$ such as taking the journey of $\mathrm{Kamal}^{3}$ and gaining self-awareness, always seeks others' attention to attract the energy of the second type. In order to obtain this self-attraction, he starts showing off. Therefore, if the individual obeys only the outer veiling, the consciousness emissions of their showing off are enough to render them qualitatively unveiled.

The qualitative veil (the elimination of the need of ostentation), is a principle even in team sports or any other

\footnotetext{
${ }^{2}$ The attraction of important matters can consume our attention and overcome the attraction of other matters and affect our need for them. Important matters' attraction cause such a motivation that they make other motivations fade away. Therefore, when motivation to perform an act exceeds the motivation to follow other demands, it is called the "transcendent motivation' compared to the lesser motivation. (Human insight, M.A. Taheri)

${ }^{3}$ The term Kamal literally means completeness and refers to the human's spiritual growth toward completion (perfection). It includes self-realization and self-awareness, meaning clarity of vision about the universe, where we have come from and for what purpose, and where we are heading. It is attaining possessions, which are transportable to the next life, and includes the perceptions such as Unity, the magnificence of the Beloved, His presence,
} 
group activity. For example, in a soccer team, if each player, in order to show off and express himself, without considering the collective benefit and group movement, tries to score by himself so he becomes known as the top scorer, the team would never be successful. The successful team's players always consider the entire team, and not just themselves. The need of ostentation or the energy of the second type causes each person to move to express him/herself and not to strive toward the team's goal. But when the human existence is glorified with the sun of the transcendent motivation, naturally, one does not notice the lesser sparkling stars of desires within, like the desire to show off and the like. In other words, even though these desires still exist within him, the greater motivation of attaining Kamal makes them fade away, and the individual becomes unattached to the energy of the second type.

In this issue, there is no difference between a man and a woman because there is one aspect of veiling for women and another for men. A man might have a gaudy chain around his neck and an earring in his ear, which might even appear acceptable; but because its purpose is showing off and attraction of the energy of the second type from others, it demonstrates that he is distant from veiling. A woman can also in many ways demonstrate her ostentation, through clothing or overall appearance.

An inexperienced or normal person could be considered a beggar; a beggar of attention, of affection, and, altogether, a beggar of the energy of the second type. But one of the stages of maturity is mystical maturity, which can be reached only when the individual has reached needlessness. In general, veiling is supposed to distance us from ostentation and bring us close to needlessness of the energy of the second type.

In the beginning of the creation of $\mathrm{Adam}^{4}$, the angels prostrated themselves to him. With that prostration, we somehow became familiar with the energy of the second type, and today we see its effects in ourselves. Every normal person, from birth onward, has this natural tendency, and unless he goes through the process of self-awareness, its existence in him is not considered unnatural even to the extent that, psychologists consider ostentation a natural human need. This proves the extent to which the need of the energy of the second type has mingled with our Foundation ${ }^{5}$. But with mystical maturity, the individual becomes completely free of this need, not feeling the need of encouragement, attraction of attention, being praised, and, in general, the energy of the second type.

From the social perspective, also, veiling becomes a necessary principle. Signs of ostentation could appear in any dress or shape; that is, even a person with a proper outer veil

and the like, all of which are discussed throughout the book 'Human from Another Outlook,' by M.A. Taheri.

${ }^{4}$ What is meant by Adam here is not the prophet Adam. People collectively are the multiplicity of the existence of Adam, and the prophet Adam is one of them. In other words, the general truth of all people is a single being that is called "Adam" (For details please refer to 'Human Insight,' Unity of existence, M.A. Taheri).

${ }^{5}$ The Foundation software comprises the instinctive and functional parts in every creature and causes its natural functions. This software also exists in humankind. For instance, a newborn's cry and suckling mothers' milk and other behaviors throughout our lifetime exist without training in the instinctive software (Psymentology, M.A. Taheri). (complete covering) could be more noticed than a person with an apparently inappropriate veil. The root of this problem must be discovered and resolved. Reaching the true veiling demonstrates a society's maturity. A society cannot improve if it thirsts for the energy of the second type and each individual in it needs to express him/herself.

Thus, the first step for a society's spiritual growth is that in that society, the need for the above-mentioned points be minimized. Only then can this society become receptive to more complex topics and can obtain proper veiling proportionate to its mystical maturity.

\section{THE INNER VALUE}

We often consider an appropriate covering based on the existential value of an object and never provide an expensive wrapping for a non-valuable object, and, vice versa, never wrap an expensive commodity in a cheap covering (like paper). For instance, we design a box for a piece of diamond jewelry that is of high value itself. A person's covering also must be harmonious with his inner values.

The same argument of inner values is also considered in regard to society [as a whole]. Huge perceptions such as the perception of Ana-al-Haqq (I am the Truth (God)), His presence [2], existential appreciation, and understanding the truth of where we have come from, where we are going, and where we are standing, directly affect our mystical maturity and choice of covering (hijab). In other words, growth of the society's level of insight has a positive effect on its mode of covering.

Perceiving this important point that our presence [in the universe] is for a purpose, that the universe has a goal and a huge consciousness rules it (Interuniversal Consciousness ${ }^{6}$ ), that we also have an intelligent role in it, and that a constituent cannot be without intelligence and purpose in an intelligent and purposeful collection (if the universe is intelligent, we are also intelligent; and if the universe follows a plan, we also follow a plan) proves to us that our existence is valuable; therefore, according to that value, we define the manner of our presence in the society.

The universe has been designed according to 'presentation', and the value of everything becomes meaningful within it through presentation. The value of making contact between people is also part of this presentation, which reveals the shape and manner of each person's relationship with others, how they evaluate the existing connection, and what they derive from it. In fact, their motivation and manner of connection determine what they present to the universe [3].

Each person presents himself based upon the value that he has found within himself. Certainly, a nihilist person presents himself in one way, a depressed person in another way, and so on; therefore, we face infinite presentations among people that depend on their inner values.

\footnotetext{
6 Interuniversal Consciousness is the collection of consciousness, awareness, awareness, or the intelligence governing the universe (For details please refer to 'Human from Another Outlook,' M.A. Taheri).
} 


\section{ATtRACTION AND REPULSION}

Each society must find an insight through which it obtains certain values or revives values that it leaves as a heritage for future generations. In the specific subject of introducing hijab and its deep meaning to the society, some attractions must be created in the same way, because by creating repulsion we cannot expect to institutionalize veiling. When these values have not been fundamentally institutionalized in a society and there are insufficient necessary explanations of them, the final goal cannot be achieved by force and creating repulsion. [Only] when the philosophy of the veil is made clear is its establishment possible [4].

\section{CONCLUSION}

In the end, the consciousness-based alms-giving of all the beauty that the universe has granted us, can be nothing but presenting a positive consciousness to the universe. Still, in many cases, not only do we not offer this positive consciousness, but what we present to the universe is the negative emissions of ostentation. 'Hijab' is the first step in preventing the emission of this negative consciousness, so that we can then offer the universe positive consciousness as our consciousness-based alms-giving [5].

\section{REFERENCES}

[1] M. A. Taheri, Human and Insight, Armenia: Grigour Natoyasi, 2011, ch. 2, pp. 60-62.
[2] M. A Taheri, Human from another Outlook, 9th Edition, Iran: Bijan publication, 2010, ch. 4, pp. 113

[3] M. A. Taheri, Human Worldview, Iran: Tohfeh Publication, 2010, ch. 3 , pp. 115.

[4] M. A. Taheri, A Collection of Articles, Armenia: Grigour Natoyasi, 2011, ch. 4, pp. 37.

[5] M. A. Taheri, Halqeh Mysticism, Iran: Andisheye mandeghar, 2009, ch. 2, pp. 17.

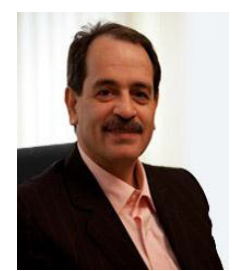

Mohammad Ali Taheri is the founder of Halqeh mysticism (Erfan-e Halqeh) or Interuniversal mysticism, and the two Iranian complementary and alternative medicines of Faradarmani and Psymentology. He holds a BS degree in Mechanics (Turkey). After three years of research on these two C.A.M medicines, the university of traditional medicine of Armenia conferred an honorary doctorate degree in the field of complementary medicine to him (2010). The International Eco-energy Academy of the Republic of Azerbaijan also conferred upon him two honorary $\mathrm{PhD}$ degrees in complementary and alternative medicine and mysticism in two consecutive years (2009 and 2010, respectively).

Dr. Mohammad Ali Taheri has introduced Faradarmani and Psymentology and their education by publishing books and articles, attending international conference, holding educational classes, and training instructors in this science for the past two decades. Eight books and numerous articles have been published by him, and more books are being prepared for publishing (it is estimated to reach around 130 titles). The published books include: Halqeh mysticism (Iran, Andisheye Mandegar, 2009), Human from another Outlook (Iran, Bijan, 2010), Human Worldview (Iran, Tohferh, 2011), Non-organic Viruses (Armenia: Grigour Natoyasi, 2011), Human and insight (Armenia: Grigour Natoyasi, 2011), and A Collection of Articles (Armenia: Grigour Natoyasi, 2011). 